\title{
The effect of transient, moderate dietary phosphorus deprivation on phosphorus metabolism, muscle content of different phosphorus- containing compounds, and muscle function in dairy cows
}

\author{
W. Grünberg, ${ }^{, 1,2}$ P. Scherpenisse,† P. Dobbelaar, ${ }^{*}$ M. J. Idink, ${ }^{*}$ and I. D. Wijnberg \\ *Department of Farm Animal Health, \\ †Institute for Risk Assessment Sciences, and \\ fDepartment of Equine Sciences, Utrecht University, 3584 CM Utrecht, the Netherlands
}

\begin{abstract}
Hypophosphatemia is a common finding in periparturient and anorectic cattle. Although the clinical relevance of hypophosphatemia in cattle is uncertain, it has been empirically associated with persistent recumbency, specifically in periparturient dairy cows. The objective of the present study was to determine if transient dietary phosphorus $(\mathrm{P})$ deprivation over a course of $5 \mathrm{wk}$, by feeding an approximately $40 \% \mathrm{P}$ deficient ration to lactating dairy cows, would result in altered muscle function or muscle $\mathrm{P}$ metabolism severe enough to present a risk for animal health and well-being. In addition, we wanted to determine the association between the plasma phosphate concentration ([Pi]) and muscle tissue $\mathrm{P}$ content to assess to what extent intracellular $\mathrm{P}$ deprivation of muscle cells could be extrapolated from subnormal plasma [Pi]. Ten healthy multiparous, mid-lactating dairy cows received a ration with a $\mathrm{P}$ content of $0.18 \%$ over a period of 5 wk. Following the P-deprivation phase, the same ration supplemented with $\mathrm{P}$ to obtain a dietary $\mathrm{P}$ content of $0.43 \%$ was fed for 2 wk. Blood and urine samples were collected regularly and muscle biopsies were obtained repeatedly to determine the $\mathrm{P}$ content in muscle tissue. Function of skeletal and heart muscles was evaluated by electrocardiography and electromyography conducted repeatedly throughout the study. Feeding the $\mathrm{P}$-deficient ration resulted in the rapid development of marked hypophosphatemia. The lowest plasma [Pi] were measured after $9 \mathrm{~d}$ of $\mathrm{P}$ depletion and were, on average, $60 \%$ below predepletion values. Plasma [Pi] increased thereafter, despite ongoing dietary $\mathrm{P}$ depletion. None of the animals developed clinical signs commonly associated with hypophosphatemia or any other

\footnotetext{
Received January 19, 2015.

Accepted April 14, 2015.

${ }^{1}$ Current address: Clinic for Cattle, University of Veterinary

${ }^{2}$ Corresponding author: waltergruenberg@yahoo.com
} Medicine Hannover Foundation, Bischofsholer Damm15, D-30173 Hanover, Germany.
\end{abstract}

health issues. Urine analysis revealed increasing renal calcium, pyridinoline, and hydroxypyridinoline excretion with ongoing $\mathrm{P}$ deprivation. Biochemical muscle tissue analysis showed that dietary $\mathrm{P}$ depletion and hypophosphatemia were not associated with a decline in muscle tissue $\mathrm{P}$ content. Electromyographic examination revealed increased occurrence of pathological spontaneous activity in striated muscles after $2 \mathrm{wk}$ of dietary $\mathrm{P}$ depletion in several cows, which could be suggestive of neuromuscular membrane instability. No effect on heart muscle activity was identified electrocardiographically. These results suggest that counter-regulatory mechanisms were sufficient to maintain normal muscle tissue $\mathrm{P}$ content during transient and moderate $\mathrm{P}$ deprivation. Muscle function was not grossly affected, although the increased occurrence of pathological spontaneous activity suggests that subclinical neuropathy or myopathy, or both, may have occurred with ongoing $\mathrm{P}$ deprivation. The results presented here indicate that plasma $[\mathrm{Pi}]$ is unsuitable for assessing muscle tissue $\mathrm{P}$ content in cattle.

Key words: phosphorus, muscle, hypophosphatemia, dairy cattle, electromyography

\section{INTRODUCTION}

Hypophosphatemia is a common finding in the periparturient dairy cow and it has been associated empirically with diseases of fresh dairy cows such as postparturient hemoglobinuria and periparturient recumbency (Goff, 2004; Grünberg, 2014). The clinical relevance of hypophosphatemia in recumbent animals is contentious but an undisputed empirical observation is that hypophosphatemia is more common or more pronounced in recumbent periparturient cows that are unresponsive to parenteral calcium administration (Goff, 2000; Metzner and Klee, 2005; Ménard and Thompson, 2007; Grünberg, 2014). Pronounced hypophosphatemia has been convincingly associated with impaired muscle function of striated and cardiac muscle in several experimental and clinical studies conducted in humans and differ- 
ent animal species not including cattle, but the precise mechanism through which phosphorus depletion or hypophosphatemia may impair muscle function is not well understood (Lotz et al., 1968; Fuller et al., 1976; Montanari et al., 1984; Subramanian and Khardori, 2000; Amanzadeh and Reilly, 2006; Grünberg, 2014).

In recent years, concerns have been voiced within the dairy industry because of incentives to reduce the $\mathrm{P}$ content in manure of ruminants to reduce pollution of soils and surface waters with $\mathrm{P}$. These incentives are believed to reduce the dietary $\mathrm{P}$ supply to dairy cattle and thereby present a risk for health and wellbeing, particularly in the periparturient period. Numerous studies have confirmed that current estimates of daily dietary $\mathrm{P}$ requirements of dairy cattle are adequate and do not jeopardize long-term health or productivity (Call et al., 1987; Valk and Sebek, 1999; Wu et al., 2000, 2001). Nevertheless, the transition from the dry phase to lactation presents several challenges for mechanisms regulating $\mathrm{P}$ homeostasis in cattle. These include the onset of lactation with rapidly increasing milk production associated with a rapid increase in $\mathrm{P}$ requirements for milk production, as well as transient feed intake depression during the periparturient period and an obviously altered equilibrium of the $\mathrm{P}$ distribution between intra- and extracellular space (Grünberg, 2014). Several field studies confirmed that hypophosphatemia is common not only in recumbent cattle but also in clinically healthy dairy cows (Metzner and Klee, 2005; Macrae et al., 2006; Ménard and Thompson, 2007).

Although the deleterious effect of severe hypophosphatemia and $\mathrm{P}$ depletion on muscle function is undisputed, the question remains whether hypophosphatemia or $\mathrm{P}$ depletion plays a role in the disease complex of the recumbent periparturient dairy cow. It is also unclear whether moderate and transient dietary $\mathrm{P}$ deprivation - as might occur in early lactating dairy cows fed a possibly $\mathrm{P}$-deficient diet that is based on ration ingredients commonly used in Europe or North America - can become severe enough to result in clinically apparent disturbed muscle function. Indeed, little is known about the degree of $\mathrm{P}$ depletion or hypophosphatemia that is required to obtain disturbed muscle function in cattle. Another point of interest is the association between plasma inorganic phosphate concentration $([\mathbf{P i}])$ and the $\mathrm{P}$ content in muscle tissue in cattle, because muscle tissue $\mathrm{P}$ depletion is often assumed based on an extrapolation from hypophosphatemia. Therefore, the objectives of the present study were to determine how far dietary $\mathrm{P}$ deprivation in dairy cows (achieved by feeding a P-deficient but otherwise balanced diet composed of common ration ingredients) alters the $\mathrm{P}$ content of muscle tissue or muscle function. We hypothesized that dietary $\mathrm{P}$ deprivation over a course of
5 wk would result in pronounced hypophosphatemia associated with a reduction of muscle tissue $\mathrm{P}$ content, which in turn may impair normal muscle function. We furthermore wanted to determine the association between plasma $[\mathrm{Pi}]$ and muscle tissue $\mathrm{P}$ content to assess to what extent intracellular $\mathrm{P}$ deprivation of muscle cells could be extrapolated from subnormal plasma [Pi].

\section{MATERIALS AND METHODS}

The national and institutional guidelines for the care and use of experimental animals were followed and all experimental procedures were approved by the Utrecht University Institutional Animal Care and Use Committee (DEC, permit no 2013.iii.03.033).

\section{Animals and Housing}

Ten healthy, lactating, nonpregnant Holstein-Friesian cows were used for this study. The required sample size for this study was calculated based on a crude but conservative estimate of the expected treatment effect on muscle tissue $\mathrm{P}$ content. The estimated effect was extrapolated from P-deprivation studies conducted in other species (Fuller et al., 1976). Cows were between 5 and 9 yr old $(6.2 \pm 1.3 \mathrm{yr}$, mean $\pm \mathrm{SD})$ and between 100 and $200 \mathrm{~d}$ in lactation. The mean BW was $615 \pm$ $54 \mathrm{~kg}$ and the mean 305-d milk yield of the previous lactation was 9,920 $\pm 1,360 \mathrm{~kg}$. All cows were healthy based on physical examination and hematological and blood biochemical examination. Cows were housed in individual tiestalls with rubber bedding, covered with sawdust, in a temperature-controlled facility.

Cows past peak lactation were selected for the present study in order to study the specific effect of $\mathrm{P}$ deprivation in lactating cows while avoiding the confounding effect of common metabolic alterations commonly occurring in the periparturient period and early lactation such as hypocalcemia, hypokalemia, or negative energy balance.

\section{Study Design and Experimental Rations}

After an acclimatization period of 2 wk (d 1 to 14), animals on study underwent dietary $\mathrm{P}$ deprivation for 5 wk (d 15 to 49). The P-deprivation phase was followed by a 2 -wk period (d 50 to 65 ) during which $\mathrm{P}$ was supplemented in excess of requirements (repletion period). The cows received the same base ration offered as TMR throughout the entire study period. This ration was based on corn silage, grass seed straw, and beet pulp and was formulated to meet the current dietary recommendations for lactating cattle (Table 1), except for the P content (NRC, 2001). During the acclimatization 
period, the diet was supplemented with $\mathrm{NaH}_{2} \mathrm{PO}_{4}$ to obtain a dietary $\mathrm{P}$ content meeting current recommendations for lactating cattle ( $0.36 \%$ of dietary $\mathrm{P}$ in $\mathrm{DM})$. The unsupplemented ration with a calculated dietary $\mathrm{P}$ content of $0.20 \%$ in DM was fed during the entire 5 -wk P-depletion phase and was approximately $40 \%$ below current recommendations (NRC, 2001). During the P-repletion phase, the ration was again supplemented with $\mathrm{NaH}_{2} \mathrm{PO}_{4}$ to obtain a dietary $\mathrm{P}$ content of $0.42 \%$ in DM (Table 1). The dietary $\mathrm{P}$ content of the ration fed during the depletion period was the lowest $\mathrm{P}$ content of an otherwise balanced ration that we were able to achieve without using P-binding additives; the dietary $\mathrm{P}$ content chosen for the ration of the repletion period is approximately equivalent to the highest dietary $\mathrm{P}$ content recommended for high-yielding dairy cows (NRC, 2001). Feed was offered twice daily ad libitum between 0600 and $0700 \mathrm{~h}$ and between 1800 and $1900 \mathrm{~h}$. Cows were milked twice daily between 0600 and $0700 \mathrm{~h}$ and between 1800 and $1900 \mathrm{~h}$.

\section{Sample Collection and Experimental Procedures}

Animal Health, Feed Intake, and Milk Production. Attitude and behavior of the study animals was monitored daily, and a complete physical examination was conducted once a week. Cows were weighed on an electronic scale at the end of the acclimatization period (d 12), after 2 wk of dietary $\mathrm{P}$ deprivation (d 30), at the end of the dietary deprivation phase (d 45), and at the end of the repletion phase (d 65).

Orts were weighed back before each feeding to determine feed intake, and feed intake on a fresh weight basis was computed for every 24 -h interval. Milk weights were recorded for every milking and the milk production per $24 \mathrm{~h}$ was calculated.

Dextrose Treatment. In an attempt to induce the so-called refeeding syndrome, a complex of symptoms attributed to pronounced hypophosphatemia resulting from parenteral dextrose treatment, a subset of 4 cows was administered a continuous intravenous dextrose infusion at the end of the P-deprivation phase (d 42; Lotz et al., 1968; Subramanian and Khardori, 2000). Dextrose was administered through a 16-gauge intravenous catheter (Angiocath, Becton Dickinson, Heidelberg, Germany) as a $20 \%$ solution at a dose rate of $300 \mathrm{mg} /$ $\mathrm{kg}$ per hour over a period of at least $6 \mathrm{~h}$. After at least $6 \mathrm{~h}$ of dextrose infusions, each cow underwent electrocardiographic (ECG) and electromyographic (EMG) examinations, as well as muscle biopsy collection as described below. The intravenous treatment was started at $0800 \mathrm{~h}$ of the treatment day and was discontinued after completion of the EMG exam, which was between 1430 and $1600 \mathrm{~h}$. Because of the unforeseeable outcome of the dextrose treatment in P-depleted cows and the intensive patient care that would have been required if animals on study developed the refeeding syndrome, we elected to subject only 4 cows to intravenous dextrose infusion.

Blood, Urine, and Feed Sample Collection. Blood samples were collected by venipuncture of a jugular vein twice a week between 0730 and $0800 \mathrm{~h}$. In the subset of 4 cows treated with intravenous dextrose, blood samples were obtained as described above from the jugular vein not used for dextrose infusion immediately before starting and immediately before discontinuing dextrose infusion.

Blood was collected from the jugular vein using a 20 -gauge needle with an evacuated tube system into 2 blood tubes containing lithium-heparin as anticoagulant (Greiner Bio-One, Kremsmünster, Austria) and were centrifuged within $30 \mathrm{~min}$ at $1,000 \times g$ for $15 \mathrm{~min}$. Harvested plasma was stored at $-21^{\circ} \mathrm{C}$ until analyzed as described below.

Urine was collected by perineal stimulation once a week between 0700 and 1000 h. Samples of spontaneously voided urine were stored at $-21^{\circ} \mathrm{C}$ until analyzed as described below.

Table 1. Ingredients (\% of DM) and composition ( $\mathrm{g} / \mathrm{kg}$ of DM unless otherwise noted) of experimental rations during the acclimatization, depletion, and repletion periods ${ }^{1}$

\begin{tabular}{|c|c|c|c|}
\hline \multirow[b]{2}{*}{ Item } & \multicolumn{3}{|c|}{ Period } \\
\hline & Acclimatization & $\mathrm{P}$ depletion & $\mathrm{P}$ repletion \\
\hline \multicolumn{4}{|l|}{ Ingredient } \\
\hline Corn silage & 38.0 & 38.3 & 37.8 \\
\hline Grass seed straw & 24.1 & 24.3 & 24.0 \\
\hline Beet pulp & 26.3 & 26.5 & 26.2 \\
\hline Soybean meal & 8.4 & 8.5 & 8.4 \\
\hline Urea & 0.34 & 0.34 & 0.33 \\
\hline Coated urea & 0.97 & 0.98 & 0.96 \\
\hline Mineral mix ${ }^{1}$ & 1.06 & 1.07 & 1.06 \\
\hline $\mathrm{NaH}_{2} \mathrm{PO}_{4}$ & 0.63 & 0 & 1.2 \\
\hline \multicolumn{4}{|l|}{ Chemical analysis } \\
\hline DM (\% as fed) & 54.7 & 54.6 & 54.9 \\
\hline $\mathrm{NE}_{\mathrm{L}}(\mathrm{MJ} / \mathrm{kg}$ of $\mathrm{DM})$ & 6.11 & 6.15 & 6.07 \\
\hline $\mathrm{DVE}^{2}$ & 72.5 & 73.0 & 72.1 \\
\hline $\operatorname{OEB}^{3}(g / d)$ & 11.3 & 11.4 & 11.3 \\
\hline Starch & 138 & 119 & 138 \\
\hline $\mathrm{Ca}$ & 5.51 & 5.92 & 5.8 \\
\hline $\mathrm{K}$ & 14.2 & 14.0 & 15.1 \\
\hline $\mathrm{P}$ & 3.48 & 1.84 & 4.86 \\
\hline $\mathrm{Mg}$ & 2.17 & 1.77 & 1.9 \\
\hline $\mathrm{S}(\%)$ & 2.62 & 2.53 & 2.16 \\
\hline $\mathrm{Na}(\%)$ & 3.3 & 1.82 & 3.98 \\
\hline
\end{tabular}

${ }^{1}$ Mineral mix contained Ca $(170 \mathrm{~g} / \mathrm{kg}), \mathrm{Mg}(38 \mathrm{~g} / \mathrm{kg}), \mathrm{Na}(120 \mathrm{~g} / \mathrm{kg})$, $\mathrm{Cu}(0.73 \mathrm{~g} / \mathrm{kg}), \mathrm{Co}(0.0095 \mathrm{~g} / \mathrm{kg}), \mathrm{Mn}(1.2 \mathrm{~g} / \mathrm{kg}), \mathrm{Zn}(1.67 \mathrm{~g} / \mathrm{kg}), \mathrm{Se}$ $(0.017 \mathrm{~g} / \mathrm{kg})$, vitamin A $(280,000 \mathrm{IU} / \mathrm{kg}), \beta$-carotene $(90000 \mathrm{IU} / \mathrm{kg})$, and vitamin $\mathrm{E}(900 \mathrm{IU} / \mathrm{kg})$.

${ }^{2} \mathrm{DVE}=$ intestinal digestible protein (Tamminga et al., 1994).

${ }^{3} \mathrm{OEB}=$ degraded protein balance (Tamminga et al., 1994). 
Feed samples were collected once a week from the feed bunk immediately after feeding and were analyzed for their DM and P contents. Dry matter was determined by atmospheric oven drying at $100^{\circ} \mathrm{C}$ to constant weight and dietary $\mathrm{P}$ content by inductively coupled plasma mass spectrometry.

ECG Examination. Electrocardiographic examinations were conducted once a week between 1000 and $1100 \mathrm{~h}$ using standard base-apex lead recordings (Mindray Beneview T5 patient monitor, Mindray Nanshan, Shenzhen, China). Electrocardiographic examinations were also conducted on the cows treated with intravenous dextrose after $6 \mathrm{~h}$ of continuous infusion. The minimum length per recording was $2 \mathrm{~min}$, which was screened for the presence of cardiac arrhythmias. If no arrhythmias were detected, a sequence of $30 \mathrm{~s}$ from each recording with the best quality for further examination was chosen and studied to determine the lengths of PR, $\mathrm{QT}$, and RR intervals, as well as the PR, ST, and TQ segments (DeRoth, 1980).

EMG Examination. At the beginning of the experiment, a subset of 8 cows was arbitrarily selected to undergo repeated EMG examination throughout the study to detect signs of muscular dysfunction by means of motor unit action potential (MUAP) analysis and interference pattern analysis (IPA; Finsterer et al., 1997; Rubin, 2012). The EMG examinations were conducted at the end of the acclimatization phase $(\mathrm{d}$ 9), after 2 wk of dietary P deprivation (d 29), after 4 wk of $\mathrm{P}$ deprivation (d 39), and after 2 wk of dietary $\mathrm{P}$ repletion ( $\mathrm{d}$ 60). The subset of 4 cows treated with intravenous dextrose at the end of the P-deprivation phase was randomly selected from the group of cows included in the EMG analyses. On these cows, an additional EMG exam was conducted at the end of a $6-\mathrm{h}$ dextrose infusion period (d 42), while the animals were still connected to the dextrose infusion.

The EMG recordings were always conducted and analyzed by the same investigator (IDW), as described in earlier studies in horses (Wijnberg et al., 2004). Briefly, the electrical activity in 3 different muscles was determined at rest to evaluate spontaneous activity and during voluntary contraction to assess the properties of isolated MUAP and interference patterns (Liguori et al., 1997). The firing frequency, pathological spontaneous activity (PSA), MUAP and interference patterns of the lateral vastus (VL), subclavian (SC), and intercostal (IC) muscles were recorded at the different examination times using portable equipment (Viking Quest EMG system; Nicolet Biomedical Inc., Madison, WI; Kimura, 2001, Daube and Rubin, 2009). The EMG were made by use of disposable concentric 26-gauge, 50-mm and 21-gauge, 100-mm EMG needle electrodes (MEDcat, Emmen, the Netherlands). Cows were placed in stocks in a calm environment and remained unsedated for the examination. Motor unit action potentials of the VL muscle were generated by inducing voluntary muscle contractions by pushing and pulling on the cow to induce a weight shift onto the limb being examined. If necessary, the contralateral limb was lifted with the help of a cotton rope to assist weight shifting. The MUAP of the IC and SC muscles were recorded with the cow standing calmly in the stocks. No extra manipulation was required to induce MUAP in these muscles.

Muscle Biopsy Collection. Muscle biopsies from the VL muscle were obtained from all animals on the days that EMG examinations were conducted (d 9, 29, 39, and 60). In cows subjected to an EMG exam, the muscle biopsy was collected immediately following the EMG examination from the limb not used for EMG study. Cows selected for intravenous dextrose infusion were biopsied on the day of dextrose treatment (d 42) at the end of the infusion period and after completion of the EMG exam. After surgical preparation and local anesthesia of the skin with $1 \mathrm{~mL}$ of procaine $4 \%$, a small stab incision was made through the skin at the biopsy site located halfway between hip and stifle joint and approximately $5 \mathrm{~cm}$ cranial of the femoral bone. Muscle tissue specimens were collected with the technique using a suction-modified Bergstrom muscle biopsy needle (6-mm diameter, Walther Veterinärinstrumente, Baruth, Germany; Tarnopolsky et al., 2011). Two specimens, each of approximately 0.2 to $0.3 \mathrm{~g}$, were obtained at each sampling time. Collected muscle tissue was submerged in liquid nitrogen within $10 \mathrm{~s}$ of collection and stored in liquid nitrogen until processed for further analysis as described below.

\section{Analyses}

Plasma Biochemical Analysis. Plasma [Pi] was determined spectrophotometrically (ammonium molybdate method), and total calcium concentration ([Ca]) was determined by indirect potentiometry (ion selective electrodes) using an automated analyzer (DXC600, Beckman Coulter Inc., Brea, CA). Total protein concentration was determined by refractometry using a temperature-controlled refractometer.

Urine Biochemical Analysis. Stored urine samples were thawed at room temperature and vortexed for $10 \mathrm{~s}$ immediately before biochemical analysis. Urine concentrations of creatinine (Crea, picric acid method), $\mathrm{Pi}$ (ammonium molybdate method), and Ca (indirect potentiometry) were analyzed on an automated analyzer (DXC-600, Beckman Coulter Inc.).

From a subset of 4 randomly selected cows, urine samples obtained at the end of the acclimatization pe- 
riod (d 15), after $1 \mathrm{wk}(\mathrm{d} 22), 3 \mathrm{wk}$ (d 36), and $5 \mathrm{wk}(\mathrm{d}$ 50 ) of dietary $\mathrm{P}$ deprivation, and after 1 wk of dietary $\mathrm{P}$ repletion (d 57) were analyzed for pyridinoline and desoxypyridinoline as surrogate parameters for resorptive activity of bone tissue. Pyridinoline and desoxypyridinoline were analyzed by HPLC as described elsewhere (Kraenzlin et al., 2008). All compounds measured in urine were expressed as amount per gram of Crea to correct for variation in urine density.

EMG Examination. A total of 108 muscle recordings from 3 muscles of 8 cows obtained from 4 to 5 EMG sessions per animal were examined. Insertional activity, PSA, MUAP, satellite potentials, IPA, and firing frequency were recorded and studied in each muscle. The occurrence of PSA was determined outside the endplate region at the same site from where MUAP were obtained. Four types of PSA were differentiated: fibrillation potentials, positive sharp waves, complex repetitive discharges, and (neuro)myotonia. Pathological spontaneous activity was counted as such when occurring in at least 2 locations within the same muscle; the incidence of PSA was categorized semiquantitatively into 4 groups from 0 (no PSA) to +++ (very frequent PSA; Georgesco and Salerno, 2000).

For quantitative MUAP analysis, amplitude, duration, number of phases, and number of turns were automatically calculated and obtained from at least 20 MUAP per muscle, as described previously (Wijnberg et al., 2002, 2004). For each superimposed MUAP, the amplitude was measured from the maximum negative to the maximum positive peak value. Duration of a MUAP was measured from the initial deflection from baseline to the final return to baseline, and the end of the MUAP was corrected manually if necessary. A phase was defined as the part of the signal between each crossing of the baseline and was counted as the number of baseline crossings plus 1. A turn was defined as each time the signal changed direction independent of crossing the baseline. For each muscle, 25 to 30 MUAP were selected and analyzed and a mean value for each of the mentioned parameters was calculated for each muscle at each EMG examination session. In addition, the size index (SI) and the MUAP area were automatically determined and included in the analysis (Wijnberg et al., 2011).

For interference pattern analysis, the low frequency filter was set at $20 \mathrm{~Hz}$, the high frequency filter at 10 $\mathrm{kHz}$, with a sampling frequency of at least $25 \mathrm{~Hz}$ (Finsterer et al., 1997; Finsterer and Fuglsang-Frederiksen, 2003). Thirty contractions at random force per segment were evaluated in each muscle. Interference patterns were analyzed by determining the maximal voluntary activity expressed as turns per second, which was calculated automatically. The muscle force induced was not literally maximal, but randomized muscle force induced after vigorous stimulation by pushing or pulling to induce weight shifts that resulted in randomized contractions. The IPA of the IC muscle was performed during spontaneous breathing patterns.

Firing frequencies were recorded using $200 \mu \mathrm{V}$ per division and $50 \mathrm{~ms}$ as sweep speed. Per muscle, 3 different insertions, thus 3 recordings, of each $120 \mathrm{~s}$ at random force were automatically measured.

Muscle Tissue Biochemical Analysis. The concentrations of ATP, ADP, AMP, and creatine were determined as described earlier (Teerlink et al., 1993; Jiang et al., 2012). Briefly, frozen muscle tissue was homogenized in $2 \mathrm{~mL}$ of ice-cold $0.66 \mathrm{M}$ perchloric acid. After centrifugation at $3,500 \times g$ and $4^{\circ} \mathrm{C}$, the supernatant was transferred into a 5 -mL glass tube. The residue was extracted and centrifuged again. Both supernatants were mixed and the volume topped up with perchloric acid to $5 \mathrm{~mL}$. Samples were stored at $-20^{\circ} \mathrm{C}$ until analyzed as described below. Before liquid chromatography-mass spectrometry (LC-MS) analysis, $1 \mathrm{~mL}$ of extract was mixed with $1 \mathrm{~mL}$ of $0.66 M$ phosphate buffer, $\mathrm{pH} 12$. The sample was refrigerated for $20 \mathrm{~min}$, centrifuged as described above, and finally diluted 5 times with water. The analysis was conducted on an LC-MS system consisting of 2 HPLC pumps, an autosampler with tray cooling set at $4^{\circ} \mathrm{C}$ (PE200 series, PESciex, Norwalk, CT), and a triple quadrupole MS detector (ABSciex, Framingham, MA) with a turbo ion spray source. The HPLC column was a hypercarb $5 \mu$ PGC $150 \times 2.1 \mathrm{~mm}$ (Thermo Scientific, Breda, the Netherlands). Eluent 1 for pump A was $8 \mathrm{mM}$ ammonium acetate, adjusted to $\mathrm{pH} 9.8$ with $25 \%$ ammonia solution, and eluent 2 for pump B was $8 \mathrm{~m} M$ ammonium acetate ( $\mathrm{pH}$ 9.8):acetonitrile (40:60; vol/vol). The flow rate was $200 \mu \mathrm{L} / \mathrm{min}$ and a gradient run was made. The first $3 \mathrm{~min}$ after injection were discarded by a divert valve. The MS was operated in multiple reaction monitoring (MRM) mode and the settings are shown in Table 2. The LC-MS was controlled by Analyst 1.4.2 software (ABSciex).

Table 2. Multiple reaction monitoring (MRM) settings of the mass spectrometer for the detection of ATP, ADP, AMP, and creatine ${ }^{1}$

\begin{tabular}{lcccc}
\hline Compound & $\begin{array}{c}\mathrm{Q} 1 / \mathrm{Q} 3(m / z) \\
\text { (qualifier) }\end{array}$ & $\begin{array}{c}\mathrm{CE} \\
(\mathrm{V})\end{array}$ & $\begin{array}{c}\mathrm{Q} 1 / \mathrm{Q} 3(m / z) \\
\text { (qualifier) }\end{array}$ & $\begin{array}{c}\mathrm{CE} \\
(\mathrm{V})\end{array}$ \\
\hline ATP & $506-79$ & -90 & $506-159$ & -43 \\
ADP & $426-79$ & -82 & $426-159$ & -39 \\
AMP & $346-79$ & -78 & $346-97$ & -37 \\
Creatine & $130-88$ & -30 & $130-41$ & -70 \\
\hline
\end{tabular}

${ }^{1} \mathrm{Q} 1$ and Q3 are the determined masses of precursor and the product ion. The quantifier MRM trace is used to quantify the results, whereas the qualifier trace is used for confirmation of the compound. $\mathrm{CE}=$ collision energy. 
The concentrations of $\mathrm{Na}, \mathrm{K}, \mathrm{P}$, and $\mathrm{Mg}$ in the solution containing the tissue homogenate were determined by inductively coupled plasma mass spectrometry (Braselton et al., 1997). The concentration of acid soluble Pi of the homogenate was determined spectrophotometrically (ammonium molybdate method) on an automated analyzer (DXC-600, Beckman Coulter Inc. Brea, CA).

The total (T) amounts of Na, K, P, Mg, acid soluble Pi, ATP, ADP, AMP, and creatine per gram wet weight of muscle tissue (TNa, TK, TP, TMg, TPi, TATP, TADP, TAMP, and TC, respectively) were then calculated from the concentration of each compound in the homogenate and the mass of the wet weight of each tissue specimen. The DM content of each muscle tissue specimen was determined by atmospheric oven drying to constant weight at $95^{\circ} \mathrm{C}$ for $8 \mathrm{~h}(1056 \mathrm{U}$, Termaks, Bergen, Norway).

\section{Statistical Analysis}

Data were expressed as arithmetic mean $\pm \mathrm{SD}$ or as median and interquartile range. A $P<0.05$ was considered significant. Values were log-transformed when necessary to achieve normal distribution. Repeatedmeasures ANOVA using an autoregressive(1) covariance matrix with animal ID as subject and time as random variable was used to identify differences in measured parameters over time using PROC MIXED (SAS Institute Inc., Cary, NC). Bonferroni-adjusted $P$-values were used to assess differences between sampling times whenever the $F$-test was significant. The association between parameters related to $\mathrm{P}$ homeostasis and parameters obtained from the EMG examination as well as the association between plasma $[\mathrm{Pi}]$ and different variables measured in muscle tissue were tested using multivariate linear regression analysis. To account for repeated measures within the same animal, this analysis used a dummy variable coding for each cow, which accounted for between-cow variability, thereby increasing the precision with which slope and intercept coefficients for the regression line can be estimated (Glantz and Slinker, 1990). This analytical approach enforces a uniform slope but different intercept value for each cow and is considered appropriate whenever the slopes are similar, as in this study. Dummy variables $\left(\mathrm{C}_{1}\right.$ to $\left.\mathrm{C}_{\mathrm{n}}\right)$ were defined as follows: $\mathrm{C}_{\mathrm{i}}=1$ if cow $\mathrm{i}\left(\right.$ with $\mathrm{i}<\mathrm{n}$ ), $\mathrm{C}_{\mathrm{i}}$ $=-1$ if cow $=n$, and $\mathrm{C}_{\mathrm{i}}=0$ otherwise. A paired 2-sided $t$-test was used to identify significant difference before and after dextrose infusion in the subset of animals that underwent parenteral dextrose administration. A statistical software package was used for analysis (SAS 9.3, SAS Institute Inc.).

\section{RESULTS}

All cows remained healthy and completed the entire study. In no animals did we observe signs commonly associated with P depletion or hypophosphatemia, such as obvious muscle weakness, difficulty to rise or persistent recumbency, feed intake depression, or hemoglobinuria.

\section{Dietary Phosphorus Content}

The results of the $\mathrm{P}$ analysis of the experimental ration showed good agreement of the calculated ration with the ration sampled from the feed bunk. The mean determined $\mathrm{P}$ contents of the experimental rations were $0.35,0.18$, and $0.43 \% \mathrm{P}$ on a DM basis, respectively, for the acclimatization, deprivation, and repletion phases of the experiment.

\section{Blood Biochemical Analysis}

The concentration-time curves for $\mathrm{Pi}$ and $\mathrm{Ca}$ are presented in Figure 1. Significant time effects were identified for plasma [Pi], with values declining within $48 \mathrm{~h}$ of $\mathrm{P}$ deprivation and reaching a nadir after $9 \mathrm{~d}$ of $\mathrm{P}$ deprivation (d 25). A continuous and significant increase of the plasma [Pi] was observed over $18 \mathrm{~d}$ following this nadir (Figure 1). Plasma [Pi] remained below the reference for $[\mathrm{Pi}]$ in cattle $(4-7 \mathrm{mg} / \mathrm{dL})$ during the entire deprivation phase (Goff, 2000; Grünberg, 2014). Plasma [Pi] increased within $48 \mathrm{~h}$ of dietary supplementation to values in the upper reference range and remained at this level until the end of the study.

A significant time effect was identified for plasma [Ca] (Figure 1). During the repletion phase, plasma [Ca] decreased significantly relative to values measured before initiating $\mathrm{P}$ deprivation (Figure 1 ). No time effect was observed for plasma $[\mathrm{Na}],[\mathrm{K}],[\mathrm{Mg}]$, or $[\mathrm{TP}]$ (data not shown).

\section{Urine Biochemical Analysis}

The median urinary [Pi] and interquartile range were below the detection limit of $0.9 \mathrm{mg} / \mathrm{dL}$ at all sampling times and did not differ over time. A P:Crea ratio was therefore not calculated for this parameter. We detected no significant time effect on urinary Mg:Crea ratio, with values ranging from $132.0 \pm 46.8$ to 158.5 $\pm 28.8 \mathrm{mg}$ of $\mathrm{Mg} / \mathrm{g}$ of Crea at the different sampling times. The urinary Ca:Crea, pyridinoline:Crea, and desoxypyridinoline:Crea ratios at different sampling times are presented in Figure 2. A significant increase in the Ca:Crea ratio within 1 wk of dietary $\mathrm{P}$ deprivation was observed, and values remained above ac- 


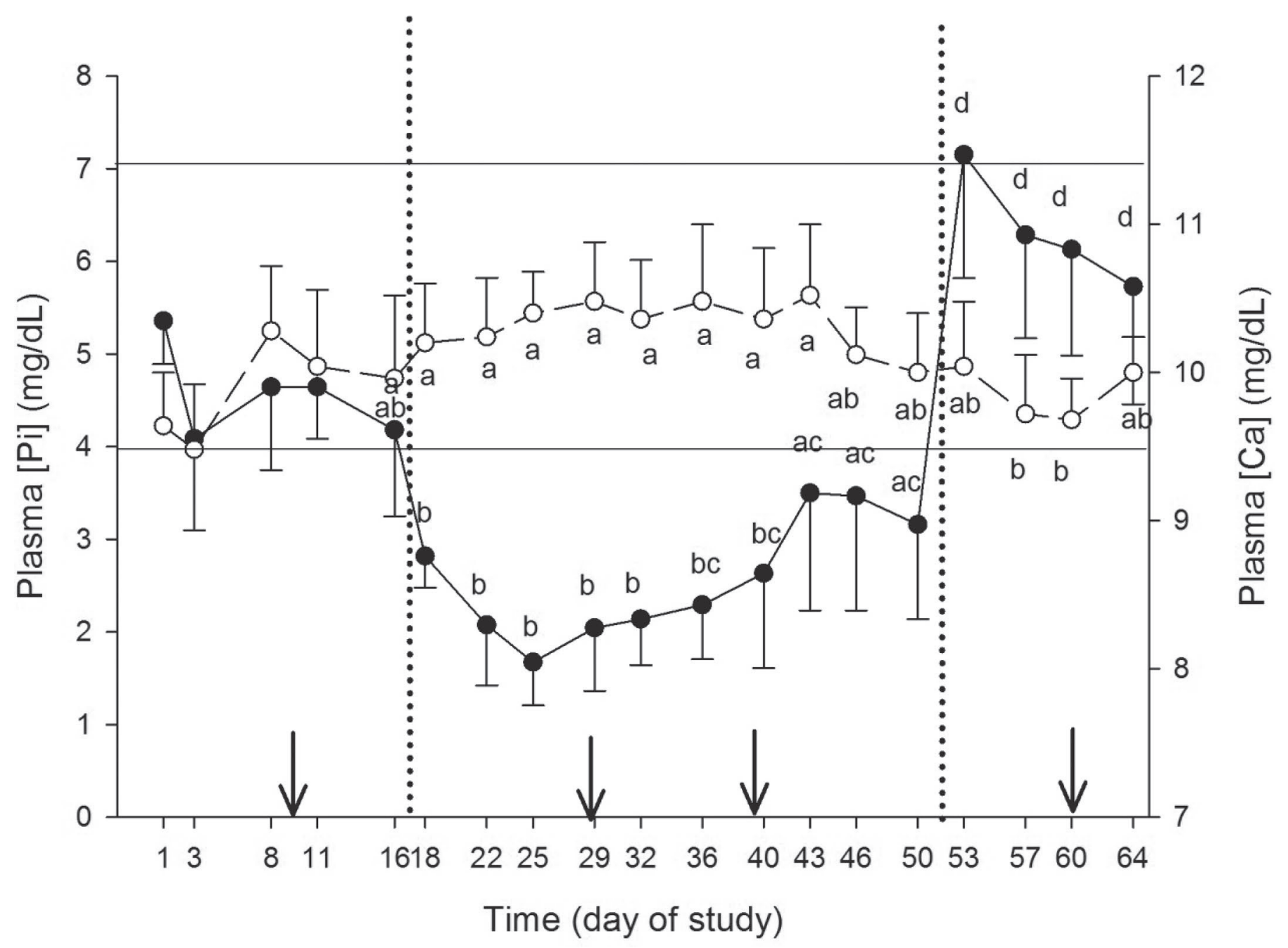

Figure 1. Mean \pm SD plasma inorganic phosphate ([Pi]; closed circles, solid line) and $\mathrm{Ca}$ ([Ca]; open circles, dashed line) over time in experimental animals. Vertical dotted lines mark start and end of the $\mathrm{P}$ depletion phase. Horizontal solid lines mark upper and lower limits of the reference for plasma [Pi] in cattle (Grünberg, 2014). Timepoints with different letters differ significantly $(P<0.05$, Bonferroni corrected). Arrows mark the times of electromyographic examination and muscle biopsy collection.

climatization period values until 1 wk after the onset of dietary $\mathrm{P}$ repletion. A numerical increase of the pyridinoline:Crea and desoxypyridinoline:Crea ratios relative to the predepletion period was observed within 1 wk of $\mathrm{P}$ deprivation that reached significance level after 3 wk of $\mathrm{P}$ deprivation (Figure 2). Both parameters returned to predepletion levels within 1 wk of dietary $\mathrm{P}$ repletion.

\section{DM Feed Intake, Milk Production, and BW}

Mean daily DMI was $20.4 \pm 2.5 \mathrm{~kg}$ and daily milk yield was $23.6 \pm 3.7 \mathrm{~kg}$ and remained constant during the entire study period. The mean BW of the cows on study was $615 \pm 54 \mathrm{~kg}, 610 \pm 53 \mathrm{~kg}, 624 \pm 51 \mathrm{~kg}$, and
$625 \pm 53 \mathrm{~kg}$ at the end of the acclimatization period (d 12), after 2 wk of $\mathrm{P}$ deprivation (d 30), at the end of the deprivation phase ( $\mathrm{d} 45$ ), and at the end of the repletion phase (d 65), respectively. No time effect on DMI, milk production, or BW was determined.

\section{ECG Examination}

Cardiac arrhythmias were not diagnosed in any of the studied cows throughout the study period. No time effects on the lengths of PR, QT, and RR intervals or the PR, ST, and TQ segments were identified on the ECG exams conducted weekly (data not shown). All parameters remained within the reference ranges for cattle reported previously (DeRoth, 1980). 

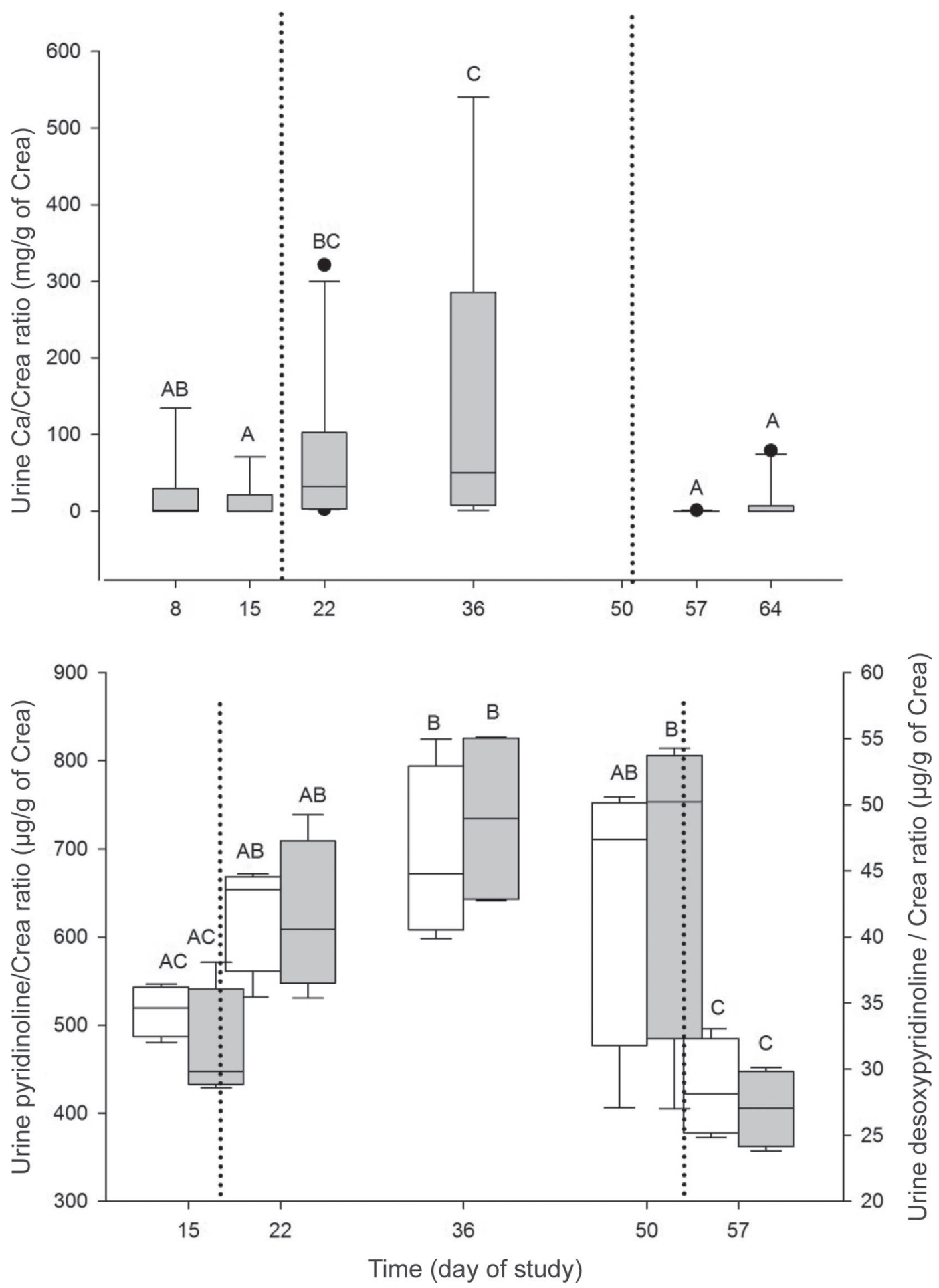

Figure 2. Urinary Ca:creatinine ratio (upper panel), urinary pyridinoline:creatinine ratio (lower panel, open boxes), and hydroxypyridinole:creatinine ratio (lower panel, gray boxes) at different sampling times. Box and whisker plots represent median (horizontal line), lower and upper quartiles (bottom and top of box, respectively), and 2nd and 9th percentiles (lower and upper end of whiskers, respectively). Outliers are represented as dots. Vertical dotted lines mark start and end of the $\mathrm{P}$ depletion phase. Timepoints with different letters differ significantly $(P<0.05$, Bonferroni corrected $)$. 


\section{Muscle Tissue Biochemical Analysis}

Muscle tissue TP, TPi, TATP, TADP, and TAMP at different sampling times are presented in Figure 3. No time effect was identified for TP, TPi, TNa, TK, or TMg in muscle tissue. In contrast, significant time effects were identified for TATP, TADP, and TAMP in muscle tissue (Figure 3). Total ATP showed an increasing trend during the deprivation phase, followed by a decline during dietary repletion. Differences were significant between both biopsies obtained during the deprivation phase (d 29 and 39) and the biopsy obtained at the end of the repletion phase (d 60; Figure 3). For TADP and TAMP, we noted a declining trend throughout the study. Values for TADP measured at the end of the acclimatization period were significantly lower than that obtained at the end of the repletion phase. For TAMP, the declining trend reached significance at the end of the deprivation phase; values remained below concentrations measured before $\mathrm{P}$ deprivation until the end of the study (Figure 3).

Total creatine in muscle tissue at the different sampling times is presented in Figure 3. The TC in muscle tissue decreased from $10.5 \pm 1.2 \mu \mathrm{mol} / \mathrm{g}$ at the end of the deprivation phase $(\mathrm{d} 39)$ to $8.6 \pm 1.0 \mu \mathrm{mol} / \mathrm{g}$ of muscle tissue wet weight at the end of the repletion phase (d 60), equivalent to a decrease of approximately $20 \%$. The tissue water content at these 2 sampling times differed by less than $2 \%$.

The DM content in muscle tissue remained constant over time, with values of $22.24 \pm 0.92 \%, 22.29 \pm 0.81 \%$, $22.70 \pm 0.55 \%$, and $22.96 \pm 1.07 \%$ at the end of the acclimatization period (d 9), after 2 wk of $\mathrm{P}$ deprivation (d 29), at the end of the deprivation phase (d 39), and at the end of the repletion phase (d 60), respectively.

Multiple stepwise regression analysis between plasma [Pi] and muscle tissue biochemical parameters yielded only weak correlations. The strongest negative association of plasma [Pi] was found with TATP (partial $\mathrm{R}^{2}$ $=0.306 ; P=0.0005)$, followed by a positive association with the muscle tissue DM content (partial $\mathrm{R}^{2}=$ 0.0917; $P=0.0280$ ) and a negative association with TK (partial $\mathrm{R}^{2}=0.0647 ; P=0.0490$ ). No direct association was identified between ATP and muscle tissue DM content or TK or between TK and DM content.

\section{EMG Examination}

Pathological spontaneous activity was recorded in 3 , 16, 18, and 14 of 24 muscles and 3, 6, 7, and 7 of 8 cows at the EMG exams conducted during acclimatization (d 9), after 2 wk of $\mathrm{P}$ deprivation (d 29), after 4 wk of $\mathrm{P}$ deprivation (d 39) and after 2 wk of $\mathrm{P}$ repletion (d 60) respectively. The most common types of PSA recorded were fibrillation potentials with a frequency of 0,13 , 15 , and 11 incidents, followed by positive sharp waves, with a frequency of $0,7,5$, and 5 incidents, complex repetitive discharge with a frequency of $2,4,5$, and 5 incidents, and neuromyotonia with $1,6,3$, and 2 incidents at d 9, 29, 39, and 60, respectively. The severity graded from 0 (no PSA) to +++ (very frequent PSA) varied considerably between animals but overall severity scores of ++ and +++ were only recorded at the examination times after 2 and 4 wk of $\mathrm{P}$ deprivation.

The parameters characterizing MUAP are presented in Table 3 stratified by examination time. Significant time effects were determined for the number of turns of the MUAP for the VL $(P=0.0237)$ and IC muscles $(P=0.0499)$.

None of the variables determined during IPA analysis showed a significant time effect for any of the studied muscles (data not shown). The firing frequencies for the 3 examined muscles at the different examinations times are summarized in Table 3. No time effect on the firing frequency was identified for any of the 3 muscles examined.

The multivariate linear regression analysis between MUAP-related variables for which either significant time effects or obvious but nonsignificant numerical changes over time were found and parameters related to the $\mathrm{P}$ homeostasis revealed weak associations only. For VL, MUAP duration was significantly associated with TP (partial $\mathrm{R}^{2}=0.160, P=0.035$ ); for IC, significant associations between TADP and MUAP amplitude $\left(\mathrm{R}^{2}\right.$ $=0.197, P=0.0092)$, number of turns $\left(\mathrm{R}^{2}=0.153, P\right.$ $=0.00168)$, and area under the MUAP $\left(\mathrm{R}^{2}=0.146, P\right.$ $=0.0015)$ were identified. For SC, significant associations were determined for plasma $[\mathrm{Pi}]$ and the MUAP amplitude $\left(\mathrm{R}^{2}=0.12, P=0.0015\right)$, and area under the $\operatorname{MUAP}\left(\mathrm{R}^{2}=0.09, P=0.0104\right)$.

\section{Dextrose Infusion Trial}

Results of the blood and muscle biochemical analysis and of the EMG examination in dextrose-infused cows obtained before and after dextrose infusion are summarized in Table 4. Animals on dextrose infusion remained healthy throughout the infusion period. Although none of the cows showed obvious signs of muscle weakness, animals subjectively appeared considerably more restless during EMG examination conducted after $6 \mathrm{~h}$ of dextrose infusion compared with other treatment days. A significant decline after dextrose treatment was observed for the plasma [Pi], but not for any of the parameters assayed in muscle tissue or the parameters determined by ECG. Numerical declines after dextrose infusion were observed for several of the examined EMG parameters. Differences in the firing frequency 


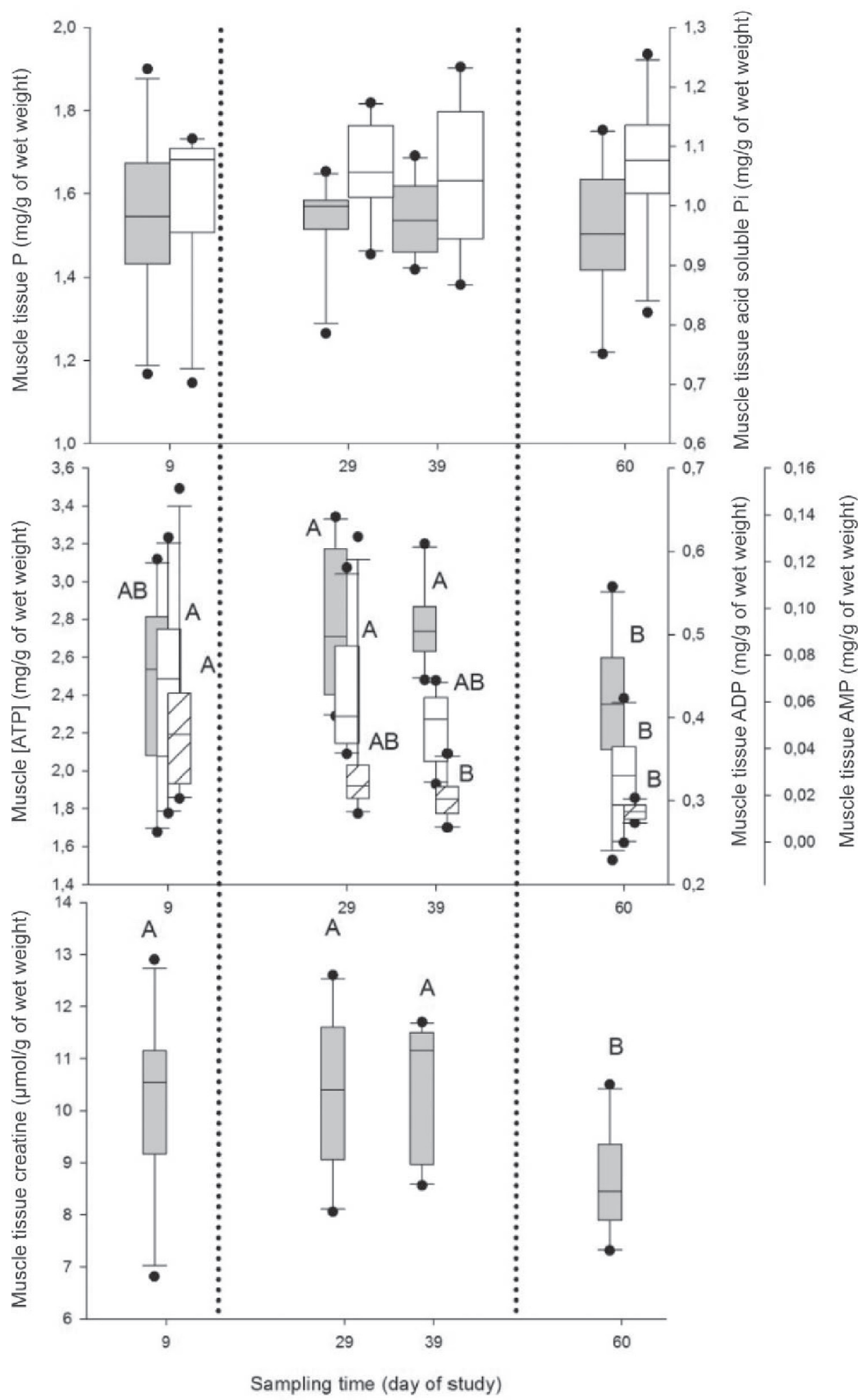

Figure 3. Muscle tissue P content (upper panel, gray boxes), acid-soluble inorganic phosphate (Pi) content (upper panel open boxes), muscle tissue ATP (middle panel, gray boxes), ADP (middle panel, open boxes), and AMP (middle panel, open hatched boxes) contents and amount of creatine (lower panel) in muscle tissue. Box and whisker plots represent median (horizontal line), lower and upper quartiles (bottom and top of box, respectively), and 2nd and 9th percentiles (lower and upper end of whiskers, respectively). Outliers are represented as dots. Vertical dotted lines mark start and end of the $\mathrm{P}$ depletion phase. Timepoints with different letters differ significantly $(P<0.05$, Bonferroni corrected). 
Table 3. Motor unit action potential (MUAP) amplitude, duration, number of phases, number of turns, the area under the MUAP, the size index of MUAP, as well as the firing frequency of the vastus lateralis, subclavian, and intercostal muscles of study animals determined during the acclimatization phase (d 9), after 2 and 4 wk of dietary P deprivation (d 29 and 39, respectively), and at the end of the P repletion period (d 60)

\begin{tabular}{|c|c|c|c|c|c|c|c|c|c|}
\hline Variable & Muscle & \multicolumn{2}{|c|}{ Day 9} & \multicolumn{2}{|c|}{ Day 29} & \multicolumn{2}{|c|}{ Day 39} & \multicolumn{2}{|c|}{ Day 60} \\
\hline \multirow[t]{2}{*}{ Amplitude $(\mu \mathrm{V})$} & Vastus lateralis & 310.02 & 38.90 & 305.81 & 89.67 & 289.90 & 81.67 & 282.25 & 79.81 \\
\hline & Intercostal & 435.41 & 121.00 & 512.90 & 262.40 & 494.92 & 153.31 & 606.41 & 87.29 \\
\hline \multirow[t]{2}{*}{ Duration (ms) } & Vastus lateralis & 6.18 & 1.13 & 6.15 & 0.37 & 6.88 & 1.99 & 5.41 & 0.85 \\
\hline & Subclavian & 7.31 & 0.76 & 7.38 & 1.87 & 7.11 & 1.13 & 6.47 & 0.65 \\
\hline \multirow{2}{*}{ No. of phases } & Subclavian & 3.32 & 0.24 & 3.38 & 0.22 & 3.32 & 0.25 & 3.14 & 0.16 \\
\hline & Intercostal & 3.16 & 0.26 & 3.22 & 0.57 & 3.42 & 0.51 & 3.45 & 0.24 \\
\hline \multirow[t]{3}{*}{ No. of turns } & Vastus lateralis & $3.19^{\mathrm{a}}$ & 0.35 & $2.91^{\mathrm{ab}}$ & 0.25 & $3.10^{\mathrm{a}}$ & 0.34 & $2.68^{\mathrm{b}}$ & 0.33 \\
\hline & Subclavian & 3.54 & 0.66 & 3.50 & 0.26 & 3.46 & 0.43 & 3.41 & 0.28 \\
\hline & Intercostal & $3.54^{\mathrm{a}}$ & 0.43 & $3.69^{\mathrm{ab}}$ & 0.62 & $4.18^{\mathrm{b}}$ & 0.84 & $4.27^{\mathrm{b}}$ & 0.35 \\
\hline \multirow[t]{2}{*}{ Area $(\mathrm{ms} \cdot \mathrm{mV})$} & Vastus lateralis & 344.64 & 75.60 & 337.55 & 80.34 & 335.97 & 97.19 & 301.72 & 102.04 \\
\hline & Subclavian & 818.14 & 228.70 & 781.64 & 205.50 & 685.47 & 172.81 & 874.62 & 281.16 \\
\hline \multirow{2}{*}{ Firing frequency } & Subclavian & 35.7 & 17.4 & 29.4 & 10.7 & 29.1 & 8.6 & 22.2 & 8.2 \\
\hline & Intercostal & 32.0 & 7.1 & 44.6 & 13.9 & 34.0 & 19.2 & 32.8 & 9.2 \\
\hline
\end{tabular}

${ }^{\mathrm{a}, \mathrm{b}}$ Values with different letters within a row differ significantly from each other $(P<0.05$, Bonferroni corrected).

determined for the 3 studied muscles before and after dextrose infusion were not significant (Table 4). Pathological spontaneous activity before dextrose treatment was recorded in 8 of 12 muscles studied and 3 of the 4 cows; PSA was recorded in all 12 studied muscles of all 4 cows at the end of the dextrose infusion. The most frequent types of PSA were fibrillation potentials recorded in 7 of 12 muscles before and 12 of 12 muscles after dextrose treatment; positive sharp waves recorded in 2 of 12 muscles and 10 of 12 muscles before and after dextrose infusion, respectively; and complex repetitive discharges identified in 4 of 12 and 9 of 12 muscles before and after dextrose, respectively. Furthermore, the EMG exams conducted before (d 39) and after $6 \mathrm{~h}$ of dextrose infusion (d 42) revealed significant declines in the number of turns $(P=0.0177)$, the number of phases $(P=0.0060)$, and the duration of $\operatorname{MUAP}(P=$ 0.043 ) of the intercostal muscles (Table 4).

\section{DISCUSSION}

The objective of the present study was to determine the effects of moderate and transient $\mathrm{P}$ deprivation on the $\mathrm{P}$ content in muscle tissue and on muscle function in lactating dairy cows. Importantly, none of the cows on study developed signs or symptoms commonly associated with hypophosphatemia such as muscle weakness, muscle stiffness, persistent recumbency, altered demeanor, decreased feed intake, or milk production or any other health issues throughout the study (Grünberg, 2014). However, EMG examinations conducted throughout the study yielded evidence that a certain degree of subclinical muscle or nerve membrane instability may have developed with dietary $\mathrm{P}$ deprivation.

The marked decline in plasma $[\mathrm{Pi}]$ in the first days of the deprivation phase confirmed the efficacy of the experimental ration in inducing hypophosphatemia in the animals on study. Despite the ongoing $\mathrm{P}$ deprivation, plasma $[\mathrm{Pi}]$ reached a nadir after $9 \mathrm{~d}$ of $\mathrm{P}$ deprivation with a continuous increase until the end of the deprivation period thereafter. This development, in combination with the pronounced increases in renal excretion of $\mathrm{Ca}$, pyridinoline, and desoxypyridinoline, indicates that counter-regulatory mechanisms, at least in the form of bone resorption, effectively prevented excessive depletion of the pool of soluble $\mathrm{P}$ in the body and resulted in a partial correction of hypophosphatemia. Consequently, dietary $\mathrm{P}$ supplementation during the repletion period was associated with a rapid increase in plasma $[\mathrm{Pi}]$ and a concomitant decline in renal $\mathrm{Ca}$, pyridinoline, and desoxypyridinoline excretion, indicative of a negative feedback of dietary $\mathrm{P}$ supplementation on the homeostatic circuits responsible for the upregulation of the $\mathrm{P}$ and Ca mobilization from bone. Pyridinoline and desoxypyridinoline in urine have been used in different species, including cattle, and are found to be useful markers for bone resorption (Seibel et al., 1992; Liesegang et al., 2000; Allen, 2003). 
Table 4. Results of blood (plasma inorganic phosphate, $\mathrm{Pi}$ ) and muscle biochemical analysis and of the electromyogram examination of study animals determined before and after $6 \mathrm{~h}$ of continuous intravenous dextrose infusion $(300 \mathrm{mg} / \mathrm{kg}$ per hour)

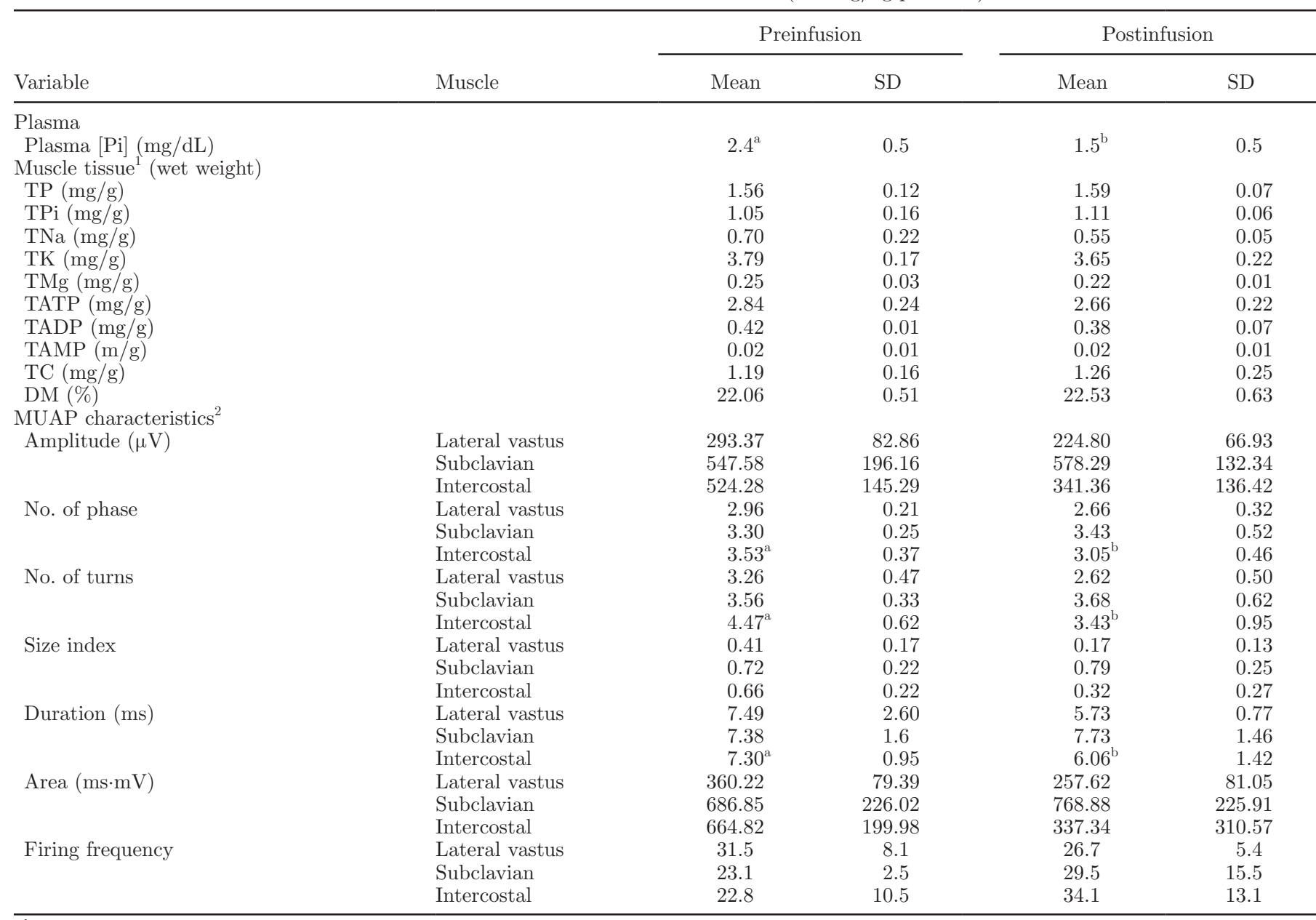

$\overline{\mathrm{a}, \mathrm{b}}$ Values with different letters within a row differ significantly from each other $(P<0.05$, Bonferroni corrected $)$.

${ }^{1} \mathrm{TP}=$ total phosphorus; $\mathrm{TPi}=$ total acid-soluble inorganic phosphate; $\mathrm{TNa}=$ total $\mathrm{Na} ; \mathrm{TK}=$ total $\mathrm{K} ; \mathrm{TMg}=$ total $\mathrm{Mg}$; $\mathrm{TATP}=$ total $\mathrm{ATP}$; $\mathrm{TADP}=$ total $\mathrm{ADP} ; \mathrm{TAMP}=$ total $\mathrm{AMP} ; \mathrm{TC}=$ total creatine.

${ }^{2}$ Motor unit action potential (MUAP) amplitude, duration, number of phases, number of turns, the area under MUAP as well as the size index of MUAP of the vastus lateralis, subclavian, and intercostal muscles.

Renal Pi excretion remained unaffected by the varying dietary $\mathrm{P}$ contents at different stages of the study, with urinary $[\mathrm{Pi}]$ remaining at the low end or below the detection limit of the analytical method. This finding is in agreement with earlier studies documenting that renal $\mathrm{Pi}$ excretion in lactating dairy cows is marginal (Grünberg, 2014).

An important finding of this study was that hypophosphatemia and dietary $\mathrm{P}$ deprivation did not alter the total $\mathrm{P}$ content or the fraction of acid-soluble $\mathrm{Pi}$ in muscle tissue, indicating that the body is able to maintain a normal intracellular $\mathrm{P}$ concentration over several weeks, despite moderate dietary $\mathrm{P}$ deprivation and pronounced hypophosphatemia. These results also indicate that plasma $[\mathrm{Pi}]$ is an unsuitable parameter to estimate muscle tissue P content. An earlier study con- ducted in Angus heifers that were subject to long-term $\mathrm{P}$ deprivation by feeding a ration approximately $40 \%$ P-deficient over several months yielded similar results. As in the present study, ongoing dietary $\mathrm{P}$ deprivation did not alter muscle tissue P content (Williams et al., 1991). A direct comparison of both studies is difficult, however, because of the difference in duration of $\mathrm{P}$ deprivation and the difference in $\mathrm{P}$ losses through the mammary gland.

Studies conducted in other species, where much more severe dietary $\mathrm{P}$ deprivation was induced by feeding diets covering less than $10 \%$ of the daily $\mathrm{P}$ requirements over several weeks, reported a significant decrease in muscle tissue $\mathrm{P}$ content that was associated with pronounced hypophosphatemia (Fuller et al., 1976, Hettleman et al., 1983). In dogs fed over 5 wk with a diet 
covering only one-tenth of the daily $\mathrm{P}$ requirement and containing a phosphate binder, a decline of $\mathrm{P}$ content in muscle tissue of $19 \%$ was reported that was associated with a serum $[\mathrm{Pi}]$ in the range of $0.9 \mathrm{mg} / \mathrm{dL}$ (Fuller et al., 1976). Mice fed a similarly P-deficient diet over 4 wk showed a decline in serum [Pi] of $55 \%$ and in muscle tissue $\mathrm{P}$ content of $45 \%$ (Hettleman et al., 1983). With the predominant difference between these and the present study being the degree of dietary $\mathrm{P}$ deprivation, we assume that dietary $\mathrm{P}$ deprivation in the present study was not severe enough to overwhelm the mechanisms regulating intracellular $\mathrm{P}$ content. Comparing these studies not only underscores the lack of a fixed association between intracellular P content and extracellular [Pi] but also indicates that the organism prioritizes and is more effective in regulating the intracellular $\mathrm{P}$ content than the extracellular [Pi]. Similar findings for the $\mathrm{P}$ content of red blood cells that remained unaffected by dietary $\mathrm{P}$ deprivation in the cows used in this study have been reported in a companion paper to the current study (Grünberg et al., 2015)

It has been suggested that the steady-state intracellular $\mathrm{Pi}$ content is partially protected against changes in plasma $[\mathrm{Pi}]$ by the properties of the sodium-linked $\mathrm{Pi}$ uptake that maintain cellular $\mathrm{Pi}$ content against an unfavorable gradient (Kemp, 1993). Intracellular P depletion thus apparently requires a threshold degree of $\mathrm{P}$ deprivation that was obviously not reached in this experiment but was reached in the studies mentioned above. In any case, the results of the present study indicate that the plasma [Pi] does not reliably reflect the intracellular $\mathrm{P}$ content of muscle tissue.

Interestingly in the present study, the lowest values for ATP, ADP, AMP, and creatine were measured at the end of the repletion phase, when $\mathrm{P}$ was supplied in excess of requirements. The constant muscle tissue DM content not only of $\mathrm{P}$ but also of $\mathrm{K}$ and $\mathrm{Mg}$ indicate that this effect is not primarily driven by intracellular $\mathrm{P}$ depletion or by an increase in tissue water content, but rather by a shift of $\mathrm{P}$ within the cell from the P-containing compounds measured in this experiment to unmeasured phosphorylated compounds. A possible explanation for the decreased ATP and creatine contents in muscle tissue during the repletion period could therefore be enhanced phosphorylation of creatine, which would explain not only the decline in muscle tissue ATP content but also the $20 \%$ decline in muscle tissue creatine, the unphosphorylated form of creatine phosphate. Enhanced phosphorylation of any unmeasured compound containing $\mathrm{P}$ and present in muscle tissue other than creatine could have resulted in reduced availability of P for ATP synthesis but would leave open the question of the whereabouts of the creatine that decreased concomitantly. We attempted to analyze creatine phosphate in muscle tissue in the present study but were unsuccessful.

Breakdown of phosphorylated adenosine nucleotide molecules, such as ATP and ADP, normally occurs in fatiguing skeletal muscles. Characteristic changes in EMG recordings with decreasing availability of ATP in muscle tissue include lower firing frequencies together with lower MUAP amplitudes, which were not observed in the present study. The occurrence of PSA as observed in this study has not been linked to intracellular ATP depletion (Zange et al., 2003). We therefore deem the changes in intracellular ATP concentration observed in the present study to be of little functional relevance.

More pronounced $\mathrm{P}$ deprivation experimentally induced over 4 wk in mice resulted not only in hypophosphatemia and $\mathrm{P}$ depletion of muscle tissue but also in significant ATP depletion that was associated with a concomitant increase of AMP, a less phosphorylated adenosine molecule (Hettleman et al., 1983). Although this result seems to contrast the findings reported here, it is likely that, as for the total $\mathrm{P}$ content in muscle tissue, dietary $\mathrm{P}$ deprivation in the present study was not severe enough to negatively affect muscle ATP content.

The amounts of $\mathrm{P}$, acid-soluble $\mathrm{Pi}, \mathrm{Na}, \mathrm{K}, \mathrm{Mg}$, ATP, ADP, AMP, and creatine in muscle tissue determined in the present study were in good agreement with values reported earlier for cattle and other species (Horvath, 1945; Fuller et al., 1976; Angerås et al., 1991; Kolb et al., 1991; Williams et al., 1991; Teerlink et al., 1993).

Repeated EMG exams conducted with ongoing dietary $\mathrm{P}$ deprivation suggest that a certain degree of membrane instability leading to irregularities in neuromuscular conductance may have occurred during dietary $\mathrm{P}$ deprivation. This is suggested by increased temporal dispersion of action potentials, expressed as an increase in the number of turns, phases, and MUAP duration, which were recorded repeatedly, although not uniformly. Spontaneous pathological activity that was observed with increased frequency toward the end of the deprivation phase has been associated with membrane instability (Liguori et al., 1997). In particular, fibrillation potentials and positive sharp waves are considered a result of membrane instability due to both myopathic and neuropathic disorders. The occurrence of PSA was not severe enough, however, to result in clinically apparent symptoms. A remarkable finding was that the increased incidence of PSA failed to return to predepletion levels despite 2 wk of dietary $\mathrm{P}$ supplementation. Membrane instability due to dietary $\mathrm{P}$ deprivation could have resulted from decreased availability of the phospholipids that are an integral part of cell membranes. The phospholipid content in muscle tissue was not measured in the present study. 
Apart from possible neuromuscular membrane instability, EMG studies provided little evidence for functional impairment of muscle fibers or functional denervation. In particular, MUAP analysis, which is considered most sensitive for the detection of myopathies, did not reveal obvious changes occurring during $\mathrm{P}$ deprivation (Liguori et al., 1997). The absence of any obvious effects of $\mathrm{P}$ depletion on muscle function are not surprising considering that muscle tissue $\mathrm{P}$ content remained constant despite ongoing dietary $\mathrm{P}$ deprivation.

Electrocardiography did not reveal arrhythmias, altered pulse rate, or changes suggestive of altered myocardial function. Cardiovascular effects of hypophosphatemia have been documented in clinical studies and case reports in humans, in which hypophosphatemia was associated with impaired myocardial contractility, decreased cardiac output, and arterial blood pressure (O'Connor et al., 1977). Hypophosphatemic human patients with serum [Pi] between 0.7 and $1.4 \mathrm{mg} / \mathrm{dL}$, a range comparable to values determined in experimental animals during the depletion phase in this study, responded to $\mathrm{P}$ supplementation with a marked increase of the left ventricular stroke volume and mean arterial blood pressure, whereas pulse rate remained unaffected (O'Connor et al., 1977). Myocardial depression that could be reversed by dietary $\mathrm{P}$ supplementation was also reported in dogs fed a diet containing one-tenth of the daily $\mathrm{P}$ requirement in addition to a phosphate binder over 5 wk (Fuller et al., 1978). In view of the lack of an effect of $\mathrm{P}$ deprivation on intracellular $\mathrm{P}$ content in the present study, the absence of cardiovascular effects is not surprising.

Dry matter feed intake, milk production, and BW remained constant throughout the study. We conclude, therefore, that feeding a ration with a dietary $\mathrm{P}$ content of $0.18 \%$ over a course of 5 wk to lactating cows does not affect feed intake, milk production, or body condition. Feed intake depression in P-deprived animals has been reported by several authors using experimental rations with higher dietary $\mathrm{P}$ content but over longer periods - at least 6 wk and, in most cases, over several months to years (Call et al., 1987; Valk and Sebek, 1999; Puggaard et al., 2014). Decreased milk production in P-deficient cows is a consistent finding of several of the studies mentioned above and is believed to be the result of feed intake depression associated with long-term $\mathrm{P}$ deprivation (Call et al., 1987; Valk and Sebek, 1999; Puggaard et al., 2014). This conclusion is supported by the findings of the present study, in which neither feed intake depression nor decreased milk production was observed despite oral $\mathrm{P}$ deprivation and marked hypophosphatemia.
Dextrose was administered intravenously to a subset of 4 cows at the end of the deprivation period in an attempt to induce clinical signs associated with acute $\mathrm{P}$ depletion that are recognized in humans and different animal species as the phosphorus depletion- or refeeding syndrome (Lotz et al., 1968; Knochel, 1981; Grünberg, 2014). The refeeding syndrome is thought to be caused by a rapid decline in intracellular ATP resulting from the shift of $\mathrm{Pi}$ into insulin-sensitive cells that is triggered by insulin. Phosphorus is then presumably shifted within the cell away from adenosine nucleotide molecules toward carbohydrate metabolites requiring P for phosphorylation (Knochel, 1981, Rasmussen, 1985). Humans that develop this syndrome show signs of disturbed muscle function, including muscle pain, breathing difficulty, or decreased cardiac output that can become severe enough to be life threatening. If recognized on time, symptoms of the refeeding syndrome can be reversed by rapid supplementation of $\mathrm{P}$ (Lotz et al., 1968; Fuller et al., 1976, 1978). Parenteral dextrose administration has also been shown to induce pronounced hypophosphatemia in cattle, albeit without any clinically apparent side effects, at least in healthy animals (Grünberg et al., 2006a,b). The significant decline in plasma $[\mathrm{Pi}]$ by over $35 \%$ during dextrose infusion observed in the present study was in agreement with earlier studies conducted in cows that were not $\mathrm{P}$ deficient. No obvious signs of muscle weakness, such as difficulty to rise, stand, or walk, were observed. Subjectively, however, the 4 cows on dextrose infusion appeared more restless when stressed during the EMG examination but not at rest. The cumulative frequency of PSA at the end of the dextrose treatment indicated an increased degree of myopathy or neuropathy possibly caused by increased neuromuscular membrane instability as mentioned above. Mild to moderate numerical changes in the contents of different $\mathrm{P}$ compounds in muscle tissue were observed that did not reach a significant level but that could be attributable to the very small number of animals that underwent dextrose infusion.

The effect of dietary $\mathrm{P}$ deprivation of varying duration in lactating dairy cattle has been investigated in numerous studies, but the present study achieved one of the lowest dietary $\mathrm{P}$ contents of published studies, with $0.18 \%$ P (Call et al., 1987; Valk and Sebek, 1999; Elizondo Salazar et al., 2013; Puggaard et al., 2014). Earlier studies focused on effects on health and productivity of long-term $\mathrm{P}$ deprivation over months to years, whereas the focus of the present study was on identifying subclinical effects of dietary $\mathrm{P}$ deprivation over a period of up to $5 \mathrm{wk}$ on muscle tissue composition and function. Muscle weakness and persistent recumbency 
is not a recognized feature of long-term $\mathrm{P}$ deprivation in dairy cattle but rather has been linked to transient or acute $\mathrm{P}$ depletion as it is believed to occur around parturition as a result of insufficient $\mathrm{P}$ intake in combination of suddenly increasing losses of $\mathrm{P}$ through the mammary gland (Valk and Sebek, 1999; Goff, 2000, 2004). Cases of presumed hypophosphatemic recumbency typically occur in herds fed rations meeting or exceeding current recommendations for daily $\mathrm{P}$ intake for dairy cattle; the underlying $\mathrm{P}$ deficiency is believed to be transient and not the result of chronic dietary $\mathrm{P}$ deprivation. We therefore elected to limit the period of $\mathrm{P}$ deprivation to $5 \mathrm{wk}$ while attempting to obtain the lowest possible dietary $\mathrm{P}$ content of an otherwise balanced lactating cow ration.

This study was conducted on past-peak lactation cows to avoid the confounding interference of other common electrolyte and metabolic imbalances of the periparturient period that would have complicated the identification of specific effects of $\mathrm{P}$ depletion. In particular, alterations of $\mathrm{Ca}$ and $\mathrm{Mg}$ as they commonly occur in early lactation interfere with homeostatic mechanisms regulation $\mathrm{P}$ homeostasis (Grünberg, 2014). The design of the present study, however, precludes uncritical extrapolation of the results to periparturient cows. Phosphorus depletion may result in a different effect on muscle tissue composition or function when associated with other metabolic alterations commonly encountered in periparturient dairy cows. Phosphorus deprivation studies have been conducted in dairy cows during the dry period and early lactation. Although several health issues such as ketosis, abomasal displacement, or rumen atony, have been diagnosed, muscle weakness or recumbency has not been reported (Puggaard et al., 2014). Studies reproducing the results reported here in periparturient cows are required to further elucidate the role of $\mathrm{P}$ in the etiology of periparturient recumbency of cows.

\section{CONCLUSIONS}

Feeding a ration with a dietary $\mathrm{P}$ content of $0.18 \%$ over $5 \mathrm{wk}$ to lactating dairy cows resulted in the rapid development of pronounced hypophosphatemia that was not associated with a decline in muscle tissue $\mathrm{P}$ content or with any clinically apparent effects on health or productivity. A remarkable finding was an increased incidence of pathological spontaneous activity in muscle tissue identified by EMG that was suggestive of subclinical myopathy or neuropathy, most likely due to membrane instability, which developed with ongoing $\mathrm{P}$ depletion. Increased occurrence of PSA and increased restlessness observed in dextrose-treated cows when stressed by experimental procedures suggest that $\mathrm{P}$ deprivation may have had a subtle effect on well-being. Feeding a ration with a $\mathrm{P}$ content of $0.18 \%$ for a period of 5 wk was not sufficient to induce clinically apparent symptoms attributable to disturbed muscle function in lactating dairy cows. We conclude, furthermore, that plasma $[\mathrm{Pi}]$ is an unsuitable parameter to assess muscle tissue $\mathrm{P}$ content.

\section{ACKNOWLEDGMENTS}

This study was funded by Productschap Zuivel (Zoetermeer, the Netherlands). The authors acknowledge the dedicated technical assistance of the caretakers of the Department of Farm Animal Health of Utrecht University.

\section{REFERENCES}

Allen, M. J. 2003. Biochemical markers of bone metabolism in animals: Uses and limitations. Vet. Clin. Pathol. 32:101-113.

Amanzadeh, J., and R. F. Reilly. 2006. Hypophosphatemia: An evidence-based approach to its clinical consequences and management. Nat. Clin. Pract. Nephrol. 2:136-148.

Angerås, U., M. Hallangeras, K. R. Wagner, H. James, P. O. Hasselgren, and J. E. Fischer. 1991. Tissue metabolite levels in different types of skeletal-muscle during sepsis. Metab. Clin. Exp. 40:1147-1151.

Braselton, W. E., K. J. Stuart, T. P. Mullaney, and T. H. Herdt. 1997. Biopsy mineral analysis by inductively coupled plasma-atomic emission spectroscopy with ultrasonic nebulization. J. Vet. Diagn. Invest. 9:395-400.

Call, J. W., J. E. Butcher, J. L. Shupe, R. C. Lamb, R. L. Boman, and A. E. Olson. 1987. Clinical effects of low dietary phosphorus concentration in feed given to lactating dairy cows. Am. J. Vet. Res. 48:133-136.

Daube, J. R., and D. I. Rubin. 2009. Needle electromyography. Muscle Nerve 39:244-270.

DeRoth, L. 1980. Electrocardiographic parameters in the normal lactating Holstein cow. Can. Vet. J. 21:271-277.

Elizondo Salazar, J. A., J. D. Ferguson, D. B. Beegle, D. W. Remsburg, and Z. Wu. 2013. Body phosphorus mobilization and deposition during lactation in dairy cows. J. Anim. Physiol. Anim. Nutr. (Berl.) 97:502-514.

Finsterer, J., and A. Fuglsang-Frederiksen. 2003. Quantification of concentric-needle-induced insertional activity by turn/amplitude analysis. J. Electromyogr. Kinesiol. 13:191-196.

Finsterer, J., B. Mamoli, and A. Fuglsang-Frederiksen. 1997. Peak-ratio interference pattern analysis in the detection of neuromuscular disorders. Electroencephalogr. Clin. Neurophysiol. 105:379-384.

Fuller, T. J., N. W. Carter, C. Barcenas, and J. P. Knochel. 1976. Reversible changes of muscle-cell in experimental phosphorus deficiency. J. Clin. Invest. 57:1019-1024.

Fuller, T. J., W. W. Nichols, B. J. Brenner, and J. C. Peterson. 1978 Reversible depression in myocardial performance in dogs with experimental phosphorus deficiency. J. Clin. Invest. 62:1194-1200.

Georgesco, M., and A. Salerno. 2000. Spontaneous activity in electromyography: Mechanisms and practical interest. Clin. Neurophysiol. 30:289-305.

Glantz, S. A., and B. K. Slinker. 1990. Primer of Applied Regression and Analysis of Variance. McGraw-Hill Book Co., New York, NY.

Goff, J. P. 2000. Pathophysiology of calcium and phosphorus disorders. Vet. Clin. North Am. Food Anim. Pract. 16:319-338.

Goff, J. P. 2004. Macromineral disorders of the transition cow. Vet. Clin. North Am. Food Anim. Pract. 20:471-494.

Grünberg, W. 2014. Treatment of phosphorus balance disorders. Vet. Clin. North Am. Food Anim. Pract. 30:383-408. 
Grünberg, W., J. A. Mol, and E. Teske. 2015. Red blood cell phosphate concentration and osmotic resistance during dietary phosphate depletion in dairy cows. J. Vet. Intern. Med. 29:395-399.

Grünberg, W., D. E. Morin, J. K. Drackley, A. M. Barger, and P. D. Constable. 2006a. Effect of continuous intravenous administration of a $50 \%$ dextrose solution on phosphorus homeostasis in dairy cows. J. Am. Vet. Med. Assoc. 229:413-420.

Grünberg, W., D. E. Morin, J. K. Drackley, and P. D. Constable. 2006b. Effect of rapid intravenous administration of 50\% dextrose solution on phosphorus homeostasis in postparturient dairy cows. J. Vet. Intern. Med. 20:1471-1478.

Hettleman, B. D., R. L. Sabina, M. K. Drezner, E. W. Holmes, and J. L. Swain. 1983. Defective adenosine-triphosphate synthesis - an explanation for skeletal-muscle dysfunction in phosphate-deficient mice. J. Clin. Invest. 72:582-589.

Horvath, S. M. 1945. The distribution of phosphorus compounds in the gastrocnemius muscle as influenced by the ageing process. Am. J. Physiol. 145:77-92.

Jiang, Y., C. Sun, X. Ding, D. Yuan, K. Chen, B. Gao, Y. Chen, and A. Sun. 2012. Simultaneous determination of adenine nucleotides, creatine phosphate and creatine in rat liver by high performance liquid chromatography-electrospray ionization-tandem mass spectrometry. J. Pharm. Biomed. Anal. 66:258-263.

Kemp, G. J. 1993. Abnormalities of Pi concentration in plasma and in cells. Clin. Chem. 39:2028-2031.

Kimura, J. 2001. Electronic systems and data analysis. Pages 39-59 in Electrodiagnosis in Diseases of Nerve and Muscle: Principles and Practice. Oxford University Press, Oxford, UK

Knochel, J. P. 1981. Hypophosphatemia. West. J. Med. 134:15-26.

Kolb, E., H. Dittrich, K. Nestler, R. Schmalfuss, and P. Siebert. 1991 Investigation on the concentration of minerals and of $\mathrm{Fe}, \mathrm{Cu}$ and $\mathrm{Zn}$ in plasma, in erythrocytes and in 10 different tissues of bulls, short scrotum bulls (Muchsen) and of oxes. Berl. Munch. Tierarztl. 104:199-205.

Kraenzlin, M. E., C. A. Kraenzlin, C. Meier, C. Giunta, and B. Steinmann. 2008. Automated HPLC assay for urinary collagen crosslinks: Effect of age, menopause, and metabolic bone diseases. Clin. Chem. 54:1546-1553.

Liesegang, A., R. Eicher, M. L. Sassi, J. Risteli, M. Kraenzlin, J. L. Riond, and M. Wanner. 2000. Biochemical markers of bone formation and resorption around parturition and during lactation in dairy cows with high and low standard milk yields. J. Dairy Sci. $83: 1773-1781$

Liguori, R., A. Fuglsang-Frederiksen, W. Nix, P. R. W. Fawcett, and K. Andersen. 1997. Electromyography in myopathy. Clin. Neurophysiol. 27:200-203.

Lotz, M., E. Zisman, and F. C. Bartter. 1968. Evidence for a phosphorus-depletion syndrome in man. N. Engl. J. Med. 278:409-415.

Macrae, A. I., D. A. Whitaker, E. Burrough, A. Dowell, and J. M Kelly. 2006. Use of metabolic profiles for the assessment of dietary adequacy in UK dairy herds. Vet. Rec. 159:655-661.

Ménard, L., and A. Thompson. 2007. Milk fever and alert downer cows: Does hypophosphatemia affect the treatment response? Can. Vet. J. 48:487-491.

Metzner, M., and W. Klee. 2005. Clinical signs and blood parameters in recumbent dairy cows with special reference to serum phosphate levels. Tierarztl. Umsch. 60:13-22.

Montanari, A., L. Borghi, A. Curti, M. Mergoni, E. Sani, G. Elia, M. Canali, A. Novarini, and A. Borghetti. 1984. Skeletal-muscle cell abnormalities in acute hypophosphatemia during total parenteral nutrition. Miner. Electrolyte Metab. 10:52-57.
NRC. 2001. Nutrient Requirements of Dairy Cattle. 7th rev.ed. Nat. Acad. Sci., Washington, DC.

O'Connor, L. R., W. S. Wheeler, and J. E. Bethune. 1977. Effect of hypophosphatemia on myocardial performance in man. N. Engl. J. Med. 297:901-903.

Puggaard, L., P. Lund, A. Liesegang, and J. Sehested. 2014. Long term effect of reduced dietary phosphorus on feed intake and milk yield in dry and lactating dairy cows. Livest. Sci. 159:18-28.

Rasmussen, A. 1985. Hypophosphatemia during postoperative glucoseinfusion. Acta Chir. Scand. 151:497-500.

Rubin, D. I. 2012. Needle electromyography: Basic concepts and patterns of abnormalities. Neurol. Clin. 30:429-456.

Seibel, M. J., S. P. Robins, and J. P. Bilezikian. 1992. Urinary pyridinium cross-links of collagen - Specific markers of bone-resorption in metabolic bone disease. Trends Endocrinol. Metab. 3:263-270.

Subramanian, R., and R. Khardori. 2000. Severe hypophosphatemiaPathophysiologic implications, clinical presentations, and treatment. Medicine 79:1-8.

Tamminga, S., W. M. Vanstraalen, A. P. J. Subnel, R. G. M. Meijer A. Steg, C. J. G. Wever, and M. C. Blok. 1994. The Dutch protein evaluation system-The DVE/OEB system. Livest. Prod. Sci. 40:139-155.

Tarnopolsky, M. A., E. Pearce, K. Smith, and B. Lach. 2011. Suctionmodified Bergstrom muscle biopsy technique: Experience with 13,500 procedures. Muscle Nerve 43:717-725.

Teerlink, T., M. Hennekes, J. Bussemaker, and J. Groeneveld. 1993. Simultaneous determination of creatine compounds and adeninenucleotides in myocardial tissue by high-performance-liquid chromatography. Anal. Biochem. 214:278-283.

Valk, H., and L. B. J. Sebek. 1999. Influence of long-term feeding of limited amounts of phosphorus on dry matter intake, milk production, and body weight of dairy cows. J. Dairy Sci. 82:2157-2163.

Wijnberg, I. D., W. Back, M. De Jong, M. C. Zuidhof, A. J. M. Van Den Belt, and J. H. Van Der Kolk. 2004. The role of electromyography in clinical diagnosis of neuromuscular locomotor problems in the horse. Equine Vet. J. 36:718-722.

Wijnberg, I. D., H. Franssen, J. H. van der Kolk, and H. J. Breukink. 2002. Quantitative analysis of motor unit action potentials in the subclavian muscle of healthy horses. Am. J. Vet. Res. 63:198-203.

Wijnberg, I. D., C. Graubner, E. Auriemma, A. J. van de Belt, and V. Gerber. 2011. Quantitative motor unit action potential analysis in 2 paraspinal neck muscles in adult Royal Dutch Sport horses. J Vet. Intern. Med. 25:592-597.

Williams, S. N., L. R. McDowell, A. C. Warnick, N. S. Wilkinson, and L. A. Lawrence. 1991. Phosphorus concentrations in blood, milk, feces, bone and selected fluids and tissues of growing heifers as affected by dietary phosphorus. Livest. Res. Rural Dev. 3:1-14.

Wu, Z., L. D. Satter, A. J. Blohowiak, R. H. Stauffacher, and J. H. Wilson. 2001. Milk production, estimated phosphorus excretion, and bone characteristics of dairy cows fed different amounts of phosphorus for two or three years. J. Dairy Sci. 84:1738-1748.

Wu, Z., L. D. Satter, and R. Sojo. 2000. Milk production, reproductive performance, and fecal excretion of phosphorus by dairy cows fed three amounts of phosphorus. J. Dairy Sci. 83:1028-1041.

Zange, J., T. Grehl, C. Disselhorst-Klug, G. Rau, K. Muller, R. Schroder, M. Tegenthoff, J. P. Malin, and M. Vorgerd. 2003. Breakdown of adenine nucleotide pool in fatiguing skeletal muscle in McArdle's disease: A noninvasive P-31-MRS and EMG study. Muscle Nerve 27:728-736. 